\title{
THE VELOCITY OF DISTRIBUTION OF SUCROSE BETWEEN PLASMA AND INTERSTITIAL FLUID, WITH REFERENCE TO THE USE OF SUCROSE FOR THE MEASUREMENT OF EXTRACELLULAR FLUID IN MAN ${ }^{1}$
}

\author{
By NORMAN DEANE, GEORGE E. SCHREINER, AND JAMES S. ROBERTSON \\ (From the Department of Physiology, New York University College of Medicine, New York \\ City, and the Medical Department, Brookhaven National Laboratory, Upton, L. I.)
}

(Submitted for publication April 16, 1951; accepted August 27, 1951)

The following study had two objectives: first, the examination of the question whether or not sucrose can be substituted for inulin in the measurement of the extracellular fluid in man; and second, the determination of how rapidly equilibrium distribution can be attained.

The use of an inulin infusion technique to measure the extracellular fluid in dog and man was initiated by Gaudino, Schwartz and Levitt $(1,2)$. These investigators used an approximately constant rate of infusion, preceded by a priming infusion, to maintain the plasma concentration of inulin at a constant level for two to 12 hours, during which period it was assumed that uniform concentration throughout the extracellular fluid would be established. After discontinuing the infusion, the total inulin excreted over a period of five hours in the dog or 12 hours in man was determined and, after correction for inulinoid blank in control blood and timed urine samples, the inulin volume of distribution was calculated by dividing total excretion by the plasma concentration at the end of the infusion. ${ }^{2,3}$ The authors con-

1 We are indebted to the Fourth (New York University Postgraduate Medical School) Medical Division for the privilege of studying patients on that service.

This study was supported by grants from the Atomic Energy Commission (AEC Contract AT [30-1]-1025) and The Commonwealth Fund.

2 Gaudino (3) has shown that comparison of the rate of disappearance of inulin from the plasma after a single injection and after prolonged, constant infusion yields data which, on mathematical analysis, conform with the assumption that in the latter circumstance the inulin is uniformly distributed through some volume of body fluid.

3 Lavietes, Bourdillon and Klinghoffer (4) endeavored to measure the extracellular fluid by calculation based on plasma concentration after the intravenous injection of a single dose of sucrose, but Schachter, Freinkel and Schwartz (5) have shown by studies with inulin that such calculations are unreliable because true plasmainterstitial fluid equilibrium never occurs and virtual equilibrium is only momentary. cluded that in the dog, uniform distribution was obtained in two hours but they presented no evidence that uniform distribution was not obtained in a shorter time.

Schwartz, Schachter and Freinkel (6), using the same technique, concluded that a maximal volume of distribution had been reached in five normal subjects who had been infused for $3.3,3.8$, $4.5,7.0$, and 7.0 hours, respectively, while in a single individual studied a maximal volume of distribution was not reached in 1.7 hours. The authors concluded that a period of five hours is sufficient to obtain essentially homogeneous distribution, but their data indicate that the critical interval in some individuals may be shorter.

The interval required to obtain homogeneous distribution will depend on the status of the circulation and the dynamics of exchange between the plasma and the interstitial fluid, and it may be anticipated that the equilibrium time will be prolonged under circumstances where the interstitial fluid is increased, or, alternatively, where the plasma-interstitial fluid exchange is sluggish. In so far as diffusion is important in effecting uniform distribution, the equilibrium time may be significantly longer with inulin (mol. wgt. = 5,200 ) than with a smaller molecule such as sucrose (mol. wgt. $=342$ ).

Sucrose is not quantitatively recovered in the urine after parenteral administration to the dog (7), indicating that it is metabolized in this species. Indeed, Abderhalden and Buadze (cited by Power and Keith [8]) demonstrated the presence of sucrose in dog plasma. However, the evidence indicates that sucrose is not metabolized in man. Keith, Wakefield and Power $(9,10)$ reported urinary recoveries ranging from 89 to 98 per cent in 12 to 24 hours after administration to subjects without renal disease. Sucrose does not enter the red cells in more than possible traces (9, 
$10)$, and it enters the cerebrospinal fluid only in traces (11).

We have examined the 24 hour urinary recovery of sucrose in eight subjects without renal disease, correcting the recovery figure for blank excretion as determined in control, timed urine samples $\left(\mathrm{U}_{\mathrm{o}} \mathrm{V}\right.$, Table $\left.\mathrm{I}\right)$. Sucrose was determined by a modification of the acid hydrolysis method of Lavietes, Bourdillon and Klinghoffer (4), using Nelson's (12) glucose method to determine the liberated glucose, but later Schreiner's (13) modification of the Roe resorcinol method proved more satisfactory. In this method the sucrose is hydrolyzed by the reagent and the liberated fructose reacts with the resorcinol. Plasma was precipitated by Nelson's (12) modification of the Somogyi zinc sulfate method.

Urine was analyzed directly unless protein was present, in which case the urine was precipitated in the same manner as the plasma. The analytical methods were checked by recoveries of aqueous and plasma solutions of known concentrations of sucrose, and in eight determinations in plasma we obtained an average recovery of 99 per cent (range 97 to 101 per cent). Omission of precipitation of protein-free urine did not affect the accuracy of recovery. Blank excretion of a sucrose-like substance under fasting and post-prandial conditions at varying rates of urine flow averaged $0.17 \mathrm{mg} . /$ min. (range 0.06 to 0.46 ) in individuals without renal disease. This does not include three subjects in whom the blank excretion was zero. The

TABLE I

Urinary recovery of sucrose after intravenous injection in man

\begin{tabular}{|c|c|c|c|c|c|}
\hline Subject & Injected & $\begin{array}{c}\text { Total } \\
\text { recovery }\end{array}$ & $\begin{array}{l}24 \mathrm{hr} . \mathrm{U}_{0} \mathrm{~V} \\
\text { (calculated) }\end{array}$ & $\begin{array}{l}\text { Corrected } \\
\text { recovery }\end{array}$ & $\begin{array}{l}\text { Per cent } \\
\text { recovery }\end{array}$ \\
\hline $\begin{array}{l}\text { H. L. } \\
\text { C. F. } \\
\text { N. D. } \\
\text { M. U. } \\
\text { J. G. } \\
\text { D. S. } \\
\text { D. S.* } \\
\text { D. S.* }\end{array}$ & $\begin{array}{r}\text { gm. } \\
12.42 \\
6.18 \\
3.87 \\
3.92 \\
5.00 \\
3.93 \\
3.31 \\
5.43\end{array}$ & $\begin{array}{r}\text { gm. } \\
12.51 \\
7.07 \\
4.67 \\
4.12 \\
5.07 \\
4.91 \\
4.27 \\
6.35\end{array}$ & $\begin{array}{c}g m . \\
0.47 \\
0.72 \\
0.75 \\
0.14 \\
0.25 \\
0.95 \\
0.99 \\
0.97\end{array}$ & $\begin{array}{c}\text { gm. } \\
12.0 \\
6.36 \\
3.92 \\
3.97 \\
4.82 \\
3.96 \\
3.28 \\
5.36\end{array}$ & 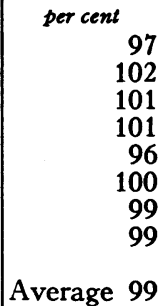 \\
\hline
\end{tabular}

* These recoveries were carried out using the calibrated infusion technique. The amount injected is obtained from IV-UV.

$\dagger 24 \mathrm{hr}$. $U_{0} \mathrm{~V}$ is the calculated 24 hour blank excretion of a sucrose-like substance. results of our experiments are given in Table I and show recovery ranging from 96 to 102 per cent, with an average figure of 99 per cent. We conclude, with Keith and his co-workers, that sucrose is not metabolized in man.

Kruhøffer (14) has shown that the rates of disappearance of sucrose and inulin (determined simultaneously) from the plasma of anesthetized (amytal), nephrectomized rabbits conform with the interpretation that diffusion dominates the distribution of these two solutes in the interstitial space. However, Kruh $\varnothing$ ffer's data do not show the ultimate volume of distribution of either solute, although they indicate that these volumes are of the same order of magnitude, slightly less than 20 per cent of the body weight. In our opinion, the rates of disappearance of substances from the blood in anesthetized animals must be used with caution since it is possible that they are gravely distorted by reduction of the peripheral circulation.

Methods for the determination of sucrose in the presence of inulin have not proved satisfactory in our hands, so we have determined the volumes of distribution of these two substances in the same individual on separate occasions. Both compounds were administered, after a priming injection, by constant intravenous infusion in order to maintain the plasma concentration approximately constant for five hours, as in the original method of Gaudino, Schwartz and Levitt (1). The total solute in the body at the end of the infusion was determined by a 24 hour urine collection with appropriate correction for blank excretion, and the volume of distribution calculated for the terminal plasma concentration corrected for plasma protein. The results of comparative studies on four edema-free subjects are given in Table II. The ratio sucrose/inulin space averaged 0.972 (range 0.936 to 1.032 ). In view of the facts that the determinations are not simultaneous and that the above ratio is less rather than greater than 1.0 we believe that our data warrant the use of sucrose in man for the determination of the extracellular fluid volume.

Determination of time required for attainment of maximal volume of distribution. The novel feature in this technique is the calculation of the virtual volume of distribution at any instant after the start of a constant intravenous infusion without the use of a priming injection. 
The virtual volume of distribution of any nonmetabolized solute, $x$, at any time, $t$, is given by the expression

$$
\mathrm{V}_{\mathrm{x}}=\frac{\sum \mathrm{IV}-\sum \mathrm{UV}}{\mathrm{P}_{\mathrm{t}}},
$$

where $V_{\mathbf{I}}$ is the virtual volume of distribution (in cc.), $\Sigma I V$ is the total quantity of solute that has been infused (in mg.), $\mathrm{\Sigma UV}$ is the total quantity of solute that has been excreted in the urine (in mg.) $)^{4}$ and $\mathrm{P}$ is the concentration of the substance in the plasma (here neglecting the plasma water content for simplicity of discussion).

Just after the infusion has been started the solute will be largely restricted to the plasma and $P$ will be large, relative to the concentration in the extracellular fluid, and $V_{\mathbf{x}}$ will consequently have a small value. If the rate of excretion increases in direct proportion to $\mathrm{P}$ (as in the case of sucrose and inulin), with the passage of time, UV (in mg./ min.) will increase from zero and approach IV (in $\mathrm{mg} . / \mathrm{min}$.), a condition that will be fulfilled only when $\mathrm{P}$ has become constant, which will not occur until a homogeneous distribution of solute has been reached. During this period of equilibration, $\mathbf{V}_{\mathbf{x}}$ will increase and approach a maximal value which will be identical with the volume of distribution to be expected at equilibrium, i.e., when $\mathrm{P}$ has been maintained constant for some period of time.

If the rate of mixing between plasma and interstitial fluid were instantaneous and if the relations between the circulation and the kidney were such as to permit instantaneous equilibration between UV and $P$, then after the infusion is started IV and UV would also come into equilibrium instantaneously, $\mathbf{P}$ would instantaneously become constant, and $\mathbf{V}_{\mathbf{x}}$ would instantaneously reach its maximal value. Such, of course, is not the case because of delay in escape from the plasma, delay in movement into the remote recesses of the interstitial fluid, and particularly because of delay in attaining equilibrium across the kidneys. ${ }^{5}$

$4 \mathrm{We}$ reserve the expressions IV and UV to indicate rates of infusion or excretion ( $\mathrm{mg} . / \mathrm{min}$.), in accordance with established convention in renal physiology, and therefore designate the total quantities infused or excreted at any time as $\Sigma I V$ and $\Sigma U V$.

- It may be noted that Michie and Michie (15) have shown that an average of 25 minutes is required to bring the pelvic urine into excretory equilibrium with the arterial plasma.
It is of critical importance in this method that the composition of the infusion be known with great accuracy and that the rate of infusion be kept very constant and known exactly, because slight errors in IV become compounded with time in the calculation of $\Sigma I V$ and therefore in all derivative calculations. (As calculated from a typical experiment, a variation of 10 per cent in the rate of infusion will produce an error of 5 per cent in $V_{8}$ after 15 minutes at a time when $\Sigma U V=0.14 \Sigma I V$.) Sucrose was infused in a 9.5 to 10.5 per cent solution with a Bowman constant infusion pump, ${ }^{6}$ delivering the infusion fluid at a rate of 0.665 to $0.700 \mathrm{cc}$. $/ \mathrm{min}$. When this pump is powered through a Sola constant voltage transformer, the rate of infusion, as checked at 30 and 60 minute intervals, remains constant with an accuracy of \pm 2 per cent. The infusion reservoir consisted of a series of 20 and $40 \mathrm{cc}$. glass bulbs with calibrated stems connected by ground glass joints, permitting the rate of infusion to be checked from time to time. The volumes delivered by the bulbs were found to be reproducible within \pm 1 per cent despite repeated autoclaving. Care must be taken to keep them chemically clean so that drainage will be complete. It is essential that a continuous check of this type be kept on the rate of the pump throughout the infusion.

A control sample of blood and a timed urine sample were collected before starting the infusion in order to determine the plasma blank and the rate of excretion of urine blank. Urine samples were collected by an indwelling catheter and the bladder was rinsed with saline and emptied with air at the end of each urine collection period. Error occasioned by renal dead space was minimized by

6 Manufactured by the Process \& Instruments Corporation, 60 Greenpoint Avenue, Brooklyn, New York.

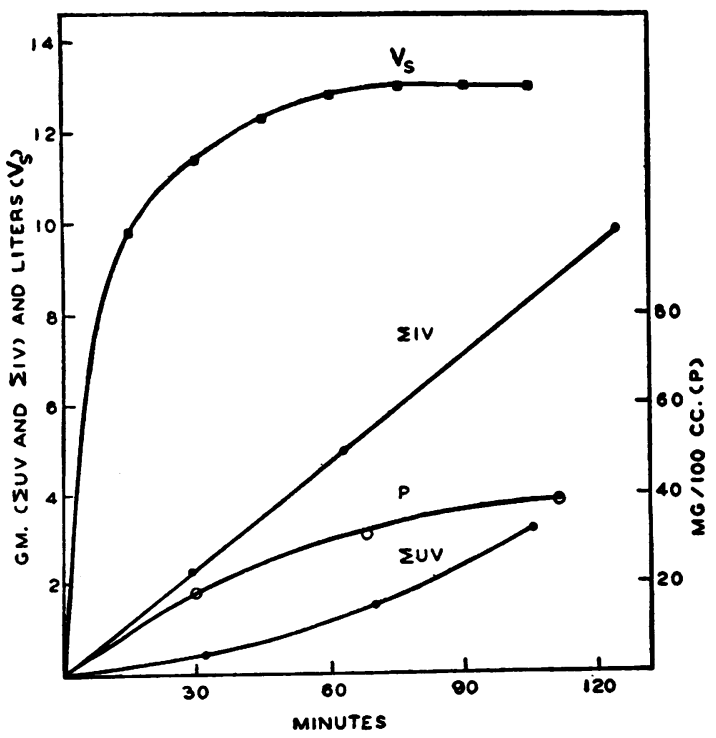

Fig. 1. Typical Experiment Showing the Virtual Volume of Distribution of Sucrose, $\mathbf{V}_{\mathbf{s}}$, During INfusion at a Constant Rate 
TABLE II

Comparative volumes of distribution of sucrose and inulin in four edema-free subjects, determined on separate occasions by the five hour infusion method

\begin{tabular}{|c|c|c|c|c|c|c|c|c|}
\hline Patient.......... & \multicolumn{2}{|c|}{ F. R. } & \multicolumn{2}{|c|}{ R.F. } & \multicolumn{2}{|c|}{ S. D. } & \multicolumn{2}{|c|}{ R. M. } \\
\hline $\begin{array}{l}\text { Sucrose space } \\
\text { Inulin space } \\
\text { Sucrose/inulin }\end{array}$ & $\begin{array}{c}\text { lilers } \\
10.20 \\
10.40 \\
0.981\end{array}$ & $\begin{array}{c}\text { per cent } \\
\text { body weight } \\
16.9 \\
17.3\end{array}$ & $\begin{array}{c}\text { liters } \\
11.81 \\
12.56 \\
0.939\end{array}$ & $\begin{array}{c}\text { per cent } \\
\text { body weight } \\
23.8 \\
25.3\end{array}$ & $\begin{array}{c}\text { liters } \\
10.14 \\
10.82 \\
0.936\end{array}$ & $\begin{array}{c}\text { per cent } \\
\text { body weight } \\
15.2 \\
16.2\end{array}$ & $\begin{array}{c}\text { liters } \\
10.80 \\
10.47 \\
1.032\end{array}$ & $\begin{array}{c}\text { per cent } \\
\text { body weight } \\
15.6 \\
15.2\end{array}$ \\
\hline
\end{tabular}

maintaining water diuresis, generally at the level of $3 \mathrm{cc} . /$ min. in adults and at comparable rates in children. The timing of blood samples, urine collection and infusion rates was noted to the nearest quarter of a minute. The amounts of sucrose used were not such as to produce any significant change in the osmotic pressure of the plasma.

The results are analyzed in the following manner. The total quantity of sucrose infused ( $I$ IV) at successive intervals is plotted against elapsed time. These points should fall on a straight line (see $\Sigma I V$, Figure 1). The total amount of sucrose excreted ( $\Sigma U V$ ) is calculated for each successive urine sample (see $\Sigma$ UV, Figure 1). These points should fall along a smooth curve and serve as a check upon the accuracy of urine collection and analysis. The plasma concentration of sucrose, as determined at various intervals, is also plotted against time (see $P$, Figure 1). ${ }^{7}$ With frequent sampling of plasma it is possible to check for deviations produced by analytical error. The virtual volume of distribution of sucrose $\left(V_{s}\right)$ (uncorrected for plasma water) at any time during the infusion is obtained by inserting the appropriate interpolated values for $\Sigma I V, \Sigma U V$, and $P$ in equation 1 (see $\mathrm{V}_{\mathrm{z}}$, Figure 1).

At the rates of infusion used here $(60.0$ to $80.0 \mathrm{mg}$./ min.) the error involved in neglecting blank excretion is less than 4 per cent of $\Sigma U V$ at 60 minutes and less than 1 per cent of $\Sigma U V$ at the end of 120 minutes. The blank excretion is usually less than 1 per cent of $\mathbf{I V}-\Sigma \mathrm{UV}$ at the end of 60 minutes. Thus errors in $V_{8}$ are minimal even if the blank excretion is omitted.

Selection of patients. The patients examined here were selected solely on the basis of showing no obvious increase in extracellular fluid. The ages ranged from two years and 10 months to 60 years. Data on a nephrotic child two years and 10 months old are included to show that the procedure is practicable within the pediatric range.

7 The term $\mathbf{P}$ may be corrected for water content in this operation, but this involves superfluous labor and it is sufficient to make the preliminary calculations in terms of $\mathbf{P}$ as analytically observed and to apply the correction for plasma water only to the definitive figure for maximal volume of distribution. This correction is effected by multiplying the final volume of distribution by the fraction of water in the plasma.

\section{RESULTS}

A typical experiment illustrating the application of the above method (which for brevity we will designate the calibrated $\mathrm{LIV- \Sigma UV}$ method) is shown in Figure 1. It will be observed that the virtual volume of distribution of sucrose $\left(V_{B}\right)$ attained a practically constant value in this patient in 70 minutes. In 14 patients without edema (Table III) the time required to attain a constant value ranged from 30 to 120 minutes and averaged 75 minutes.

The next problem is to what extent this volume of distribution approaches the maximal volume of distribution. This point was examined by comparing the results obtained by the calibrated $\mathbf{\Sigma} I V-$ SUV method with those obtained by using a prolonged equilibration time, as in the method of Gaudino, Schwartz and Levitt (which we will designate the total urine recovery method). At the end of three hours of infusion, using the calibrated $\Sigma I V-\Sigma U V$ method, a priming infusion of sucrose was administered and the infusion continued for an additional five hours with the maintenance of a constant plasma concentration as demonstrated by plasma samples taken at the end of two, three, four, and five hours. At the end of the five hour period the infusion was discontinued and urine was quantitatively collected for the next 24 hours. The volume of distribution of sucrose was calculated from the amount of sucrose recovered in the urine and the plasma concentration at the termination of the infusion.

As shown in Table IV, the results obtained by the two methods are in good agreement in three subjects. It follows that, so far as these subjects are concerned, the rate of mixing between plasma and extracellular fluid is very rapid and that, despite continuing increase in $\mathrm{P}$, this term is, within the limit of technical error, identical with the con- 
TABLE III

Maximal volume of distribution in 14 subjects measured by the calibrated infusion method

\begin{tabular}{|c|c|c|c|c|c|c|c|c|c|c|}
\hline Patient & Sex & Age & Weight & Diagnosis & $\begin{array}{l}\text { Approx. time } \\
\text { required for } \\
\text { maximal } \\
\text { volume of }\end{array}$ & $\frac{\mathrm{UV}}{\mathrm{IV}} \times 100$ & $\underset{\text { dis }}{\text { Maxin }}$ & $\begin{array}{l}\text { olume of } \\
\text { ttion }\end{array}$ & Sodi & m space \\
\hline $\begin{array}{l}\text { H. C. } \\
\text { T. G. } \\
\text { J. M. } \\
\text { S. R. } \\
\text { D. R. } \\
\text { J.P. } \\
\text { R. N. } \\
\text { L. P. } \\
\text { M.P. } \\
\text { E. L. } \\
\text { S. H. } \\
\text { R. F. } \\
\text { M. U. } \\
\text { S. D. }\end{array}$ & $\begin{array}{l}\mathbf{M} \\
\mathbf{M} \\
\mathbf{M} \\
\mathbf{M} \\
\mathbf{M} \\
\mathbf{F} \\
\mathbf{F} \\
\mathbf{F} \\
\mathbf{F} \\
\mathbf{M} \\
\mathbf{M} \\
\mathbf{M} \\
\mathbf{F} \\
\mathbf{M}\end{array}$ & $\begin{array}{l}y r s . \\
60 \\
36 \\
34 \\
14 \\
55 \\
50 \\
46 \\
65 \\
56 \\
48 \\
210 \\
14 \\
27 \\
18\end{array}$ & $\begin{array}{c}\text { kg. } \\
74.1 \\
88.4 \\
85.9 \\
47.8 \\
64.4 \\
45.9 \\
45.0 \\
61.3 \\
55.9 \\
70.0 \\
16.9 \\
49.6 \\
43.4 \\
66.7\end{array}$ & $\begin{array}{l}\text { Normal } \\
\text { Normal } \\
\text { Normal } \\
\text { Normal } \\
\text { Hyperthyroidism } \\
\text { Hyperthyroidism } \\
\text { Thyroid malignancy } \\
\text { Thyroid malignancy } \\
\text { Thyroid malignancy } \\
\text { Polycythemia vera } \\
\text { Nephrosis } \\
\text { Acute rheumatic fever } \\
\text { Rheumatoid arthritis } \\
\text { Acute rheumatic fever }\end{array}$ & $\begin{array}{r}120 \\
30 \\
60 \\
90 \\
80 \\
120 \\
105 \\
60 \\
105 \\
30 \\
30 \\
70 \\
105 \\
45\end{array}$ & $\begin{array}{l}31 \\
12 \\
23 \\
34 \\
22 \\
30 \\
13 \\
28 \\
26 \\
10 \\
3 \\
29 \\
43 \\
20\end{array}$ & $\begin{array}{r}\text { liters } \\
13.8 \\
14.3 \\
16.4 \\
7.8 \\
11.5 \\
8.4 \\
10.2 \\
-8.7 \\
11.4 \\
12.3 \\
3.7 \\
12.2 \\
9.4 \\
10.5\end{array}$ & \begin{tabular}{|c} 
per cent \\
body weight \\
18.8 \\
16.2 \\
19.1 \\
16.3 \\
17.9 \\
18.6 \\
22.6 \\
14.4 \\
20.4 \\
17.5 \\
22.0 \\
24.6 \\
21.6 \\
15.7
\end{tabular} & $\begin{array}{l}\text { liters } \\
19.1 \\
18.6 \\
= \\
= \\
\overline{-} \\
13.9 \\
12.9 \\
14.9 \\
17.2 \\
4.7 \\
= \\
-\end{array}$ & \begin{tabular}{|c} 
per cent \\
body weight \\
25.8 \\
21.0 \\
- \\
- \\
- \\
30.9 \\
21.0 \\
26.7 \\
24.6 \\
28.0 \\
$=$ \\
-
\end{tabular} \\
\hline
\end{tabular}

centration in all portions of the extracellular fluid. Since constancy of $V_{\mathbf{s}}$ was attained in all subjects listed in Table III, we presume that this conclusion is also applicable to them.

Where a major part of the infused sucrose is excreted, the term $\Sigma U V$ will be large relative to SIV and the accuracy of any calculation based on the difference, $\Sigma I V-\Sigma U V$, will be diminished. Therefore, we have shown in Table III the fraction of the administered sucrose excreted at the time when the virtual volume of distribution first became constant. This figure ranges from 3 to 43 per cent. Thus the term ( $\Sigma I V-\Sigma U V$ ) is always greater than 50 per cent of $\Sigma I V$ and the error from this source is kept to a minimum.

Simultaneous measurements of the volume of distribution of sucrose and $\mathrm{Na}^{24}$ were made in

TABLE IV

Comparison of sucrose space in three individuals as measured by the calibrated infusion method and the total urine collection method

\begin{tabular}{|c|c|c|c|c|c|c|}
\hline \multirow[b]{2}{*}{$\begin{array}{l}\text { Sucrose space } \\
\text { Calibrated infusion } \\
\text { method with changing } \\
\text { plasma concentration }\end{array}$} & \multicolumn{2}{|c|}{ R. F. } & \multicolumn{2}{|c|}{ M. U. } & \multicolumn{2}{|c|}{ S. D. } \\
\hline & $\begin{array}{l}\text { liters } \\
12.22\end{array}$ & $\begin{array}{c}\text { per cent } \\
\text { body } \\
\text { weight }\end{array}$ & liters & $\begin{array}{c}\text { per cent } \\
\text { body } \\
\text { weight }\end{array}$ & 10.53 & $\begin{array}{l}\text { per cent } \\
\text { body } \\
\text { weight }\end{array}$ \\
\hline $\begin{array}{l}\text { Sucrose space } \\
\text { Five hour infusion } \\
\text { method with constant } \\
\text { plasma concentration } \\
\text { and } 24 \text { hour urine } \\
\text { collection }\end{array}$ & 11.81 & 23.8 & 8.82 & 20.4 & 10.14 & 15.2 \\
\hline
\end{tabular}

seven patients. (Table III). It is known that sodium has a variable intracellular distribution and that the sodium space is always larger than the volume of extracellular fluid. This was the case in all patients studied here.

The volume of distribution of sucrose as determined by the $\Sigma I V-\Sigma U V$ method and corrected for plasma water ranged from 14.1 to 24.6 per cent and averaged 19 per cent of the body weight. These studies were carried out in patients with a variety of pathological disturbances, however. The volume of distribution of sucrose in the four subjects whom we have listed as "normal" ranges from 16.2 to 19.1 per cent of the body weight (average 17.6 per cent), figures that agree with those reported by previous investigators using the total urine recovery method.

\section{DISCUSSION}

The method described here affords a more practical approach to the measurement of extracellular fluid than that presented by the five hour equilibration and the total urine collection method. It has the advantage that it can be extended to patients in the pediatric range and to almost all adults, and in general a valid determination can be completed within 180 minutes. If approximately uniform distribution throughout the body fluids is not attained, the method reveals this fact by the circumstance that the virtual volume of distribu- 
tion, as here calculated, will not have attained a maximal value. Seriatim determinations during the three hours of infusion therefore afford a safeguard against sluggish mixing. The method is not applicable in its present form to subjects in the edematous state without prolongation of the infusion.

\section{SUMMARY}

We have confirmed the observations of others that sucrose is not metabolized in man (as it is in the $\operatorname{dog}$ ) and in four patients we have demonstrated by the five hour infusion-equilibration technique plus 24 hour urine collection that sucrose has the same volume of distribution, within the limits of technical error, as does inulin. Because the difference in molecular weight between sucrose and inulin may make a significant difference in the rate of equilibration within the interstitial fluid, we have substituted sucrose for inulin in a study of the kinetics of mixing between plasma and interstitial fluid by means of a calibrated infusion technique in which a priming injection is omitted.

The results obtained on four normal subjects and 10 patients with a variety of pathological disturbances show that the mixing process is of such a nature that within 30 to 180 minutes after the beginning of a sucrose infusion (without a priming dose), the plasma has for practical purposes come into equilibrium with the interstitial fluid. The volume of distribution of sucrose measured when apparent equilibrium distribution has been reached agrees in three patients with the volume of distribution as measured by the five hour infusion-total recovery method. This approach to equilibrium is attained despite the fact that the plasma concentration is still increasing, a circumstance that indicates relatively rapid mixing between plasma and interstitial fluid.

The method has the advantage that it reveals failure to attain equilibration between the plasma and extracellular fluid in any particular patient.

\section{REFERENCES}

1. Gaudino, M., Schwartz, I. L., and Levitt, M. F., Inulin volume of distribution as a measure of extracellular fluid in dog and man. Proc. Soc. Exper. Biol. \& Med., 1948, 68, 507.

2. Gaudino, M., and Levitt, M. F., Inulin space as a measure of extracellular fluid. Am. J. Physiol., 1949, 157, 387.

3. Gaudino, M., Kinetics of distribution of inulin between two body water compartments. Proc. Soc. Exper. Biol. \& Med., 1949, 70, 672.

4. Lavietes, P. H., Bourdillon, J., and Klinghoffer, K. A., The volume of the extracellular fluids of the body. J. Clin. Invest., 1936, 15, 261.

5. Schachter, D., Freinkel, N., and Schwartz, I. L., Movement of inulin between the plasma and interstitial fluid. Am. J. Physiol., 1950, 160, 532.

6. Schwartz, I. L., Schachter, D., and Freinkel, N., The measurement of extracellular fluid in man by means of a constant infusion technique. J. Clin. Invest., 1949, 28, 1117.

7. Keith, N. M., Power, M. H., and Peterson, R. D., The distribution and recovery of intravenously injected sucrose. Am. J. Physiol., 1934, 109, 62.

8. Power, M. H., and Keith, N. M., Experiments on the distribution and renal excretion of sucrose injected intravenously in dogs. J. Biol. Chem., 1936, $114,1 \times x x$.

9. Keith, N. M., Wakefield, E. G., and Power, M. H., The excretion and utilization of sucrose when injected intravenously in man. Am. J. Physiol., 1932, $101,63$.

10. Keith, N. M., and Power, M. H., The urinary excretion of sucrose and its distribution in the blood after intravenous injection into normal men. Am. J. Physiol., 1937, 120, 203.

11. Masserman, J. H., Effects of intravenous administration of hypertonic solution of sucrose. Bull. Johns Hopkins Hosp., 1935, 57, 12.

12. Nelson, N., A photometric adaptation of the Somogyi method for the determination of glucose. J. Biol. Chem., 1944, 153, 375.

13. Schreiner, G. E., Determination of inulin by means of resorcinol. Proc. Soc. Exper. Biol. \& Med., 1950, 74, 117.

14. Kruhфffer, P., The significance of diffusion and convection for the distribution of solutes in the interstitial space. Acta physiol. Scandinav., 1946, 11, 37.

15. Michie, A., and Michie, C., The attainment of equilibrium between plasma and urine, with reference to the measurement of renal clearances. J. Urol., 1951, 66, 518. 